\section{FACTORS ASSOCIATED WITH WORK RELATED STRESS AMONG NURSING OFFICERS IN A MAJOR TERTIARY CARE HOSPITAL IN SRI LANKA}

\author{
P.H. WARNAKULASSRIYA ${ }^{\mathrm{a} 1}$ AND S.M. ARNOLD \\ ${ }^{a}$ MSc (Medical Administration) MSc (Community Medicine), Medical Superintendent, Base Hospital, Balapitiya, Sri Lanka \\ ${ }^{\mathrm{b}} \mathrm{MD}$ (Community Medicine), Director, Quarantine Unit, Ministry of Health, Sri Lanka
}

\begin{abstract}
Stress is the harmful physical and emotional response caused by an imbalance between the perceived demands and the perceived resources and abilities of individuals to cope up with those demands. To determine the factors associated with work stress among nursing officers in the major tertiary care hospital in Sri Lanka. Descriptive cross-sectional study over a three-month period was carried out among 361 nurses in ward settings at National Hospital Sri Lanka. Two-stage stratification with simple random sampling method was used to select the sample. Nursing Stress Score was used to measure the stress. In-ward nursing officers work related stress was positively and significantly associated with increased number of night shifts, double shifts and inadequacy of the nursing and minor staff. Developing systems for effective two-way communication, proper recruitment of health staff, counseling should be made available.
\end{abstract}

KEYWORDS: Work Related Stress, Nursing Officers, Tertiary Care Hospital

The health services are delivered through an extensive network of primary-to-tertiary level community centres, hospitals, and dispensaries. In the Sri Lankan health system, nurses have a valuable role in caring for patients in order to avoid illness and help the evolving health status of the nation. Sri Lankan health-care delivery review recognized that a significant shortage of talented nurses exists in almost all medical institutions in all places (Abeykoon, 2003), (Jayasekara, 2009).

The nursing population of Sri Lanka is largely represented by a female. The female nurse plays a significant role as a mother, a wife, and a daughter in their own life in addition to the role of a nurse (De Silva and Rolls, 2010). Therefore, as a group, they are prone to encounter stressful situations more often compared to other professions.

\section{MATERIALS AND METHODS}

A hospital-based descriptive cross-sectional study was carried out to determine factors associated work related stress among nursing officers in a major tertiary care hospital of Sri Lanka.

This study was conducted at the National Hospital of Sri Lanka (NHSL) which is the largest teaching hospital consisting of 3300 beds and functions as the National Referral Centre for medical and surgical care in Sri Lanka. The NHSL has 106 Wards, 12 Intensive Care Units and 35 Operating Theatres in addition to other specialized units. There are 1328 nursing officers (excluding nursing sisters) attached to these wards. The study population consisted of nursing officers attached wards. Sample size calculated using formula by Lwanga \& Lemeshow (Lwanga et al., 1991) was 427. Two-stage stratification with a simple random sampling method was used.

Stress Scale developed by Pamela Gray-Toft and James G. Anderson (1981), was used to measure the level of stress among nursing officers. Nurses were requested to mention on a 4-point scale how frequently they experienced situations considered as stressful in the current place of the unit in which they work. The scale has consisted of 34 Likert-scale questions including choices. The mean stress score for each subscale was measured and the mean total score of participants was calculated. Each option carried out marks as follows, never (0), occasionally (1), frequently (2) and very frequently (3).

\section{RESULTS}

The sample consisted of 427 nursing officers and 361 responded with a response rate of $84.5 \%$.

There was no statistically significant difference in the mean rank value of stress score with age, marital status, educational level, and income level and significant association was observed with availability of children (Table 1).

${ }^{1}$ Corresponding author 
Significant association with work related stress was observed in number of night shifts, number shifts per month, number of double shifts per day in a row, inadequacy of the nursing and minor staff in the ward, unable to adjust to the shift work and salary adequacy to work (Table 2).

Binary logistic regression shows that there is no association was observed in availability of children and salary adequacy to work which was significantly associated with Mann-Whitney test. Significant association with work related stress was observed in number of night shifts, number of double shifts per day in a row, inadequacy of the nursing and minor staff in the ward with binary logistic regression which was already associated non parametric test. Number of shifts per month and difficult to adjust to shift work which was significantly associated with Mann-Whitney test is not associated with binary logistic regression (Table 3).

Table 1: Association of work related stress with other factors

\begin{tabular}{|l|c|c|c|c|}
\hline Variable & Frequency & Mean rank & Mann-Whitney U test & P value \\
\hline Age up to 35 & 303 & 181.92 & 8508.5 & 0.702 \\
Age more than 35 & 58 & 176.2 & & \\
\hline Married & 205 & 175 & 14773.5 & 0.215 \\
Others* & 156 & 188.8 & & \\
\hline Income up to Rs.60,000 & 56 & 181.8 & 8281.5 & 0.719 \\
Income more than Rs.60,000 & 305 & 176.3 & & \\
\hline No children & 214 & 193.8 & 12978.5 & $<\mathbf{0 . 0 5}$ \\
Have children & 147 & 162.3 & & \\
\hline
\end{tabular}

Table 2: Association of stress with work related factors

\begin{tabular}{|l|c|c|c|c|}
\hline Variable & Frequency & Mean rank & Mann-Whitney U test & P value \\
\hline Up to 6 night shifts per shifts/month & 64 & 140.3 & 6902.5 & $<0.001$ \\
More than 6 night shifts per month & 297 & 189.8 & & \\
\hline Up to 40 shifts per month & 155 & 160 & $127,295.00$ & $<0.001$ \\
More than 40 shifts per month & 206 & 196.5 & & \\
\hline Up to 10 double shifts per month in a row & 255 & 165.5 & 9574.5 & $<0.001$ \\
More than 10 double shifts per month & 106 & 218.5 & & \\
\hline Adequate of nursing staff in the ward & 132 & 143.9 & 10226.5 & $<0.001$ \\
Not adequate of nursing staff in the ward & 229 & 202.3 & & \\
\hline Adequacy of minor staff in the ward & 68 & 122.9 & 6012 & $<0.001$ \\
Not adequate of minor staff in the ward & 293 & 194.8 & & \\
\hline Able to adjust to shift work & 130 & 163.3 & 12720 & $<0.016$ \\
Unable to adjust to shift work & 231 & 190.9 & & \\
\hline Adequately supervised by supervisor & 291 & 177.6 & 9211 & \\
Not adequately supervised by supervisor & 70 & 195 & & 0.214 \\
\hline Adequately support from supervisor & 279 & 177.8 & 10560.5 & \\
Not adequately support from supervisor & 82 & 192 & & $<0.585$ \\
\hline Work experience up to 3 years & 31 & 189.19 & 4861 & \\
Work experience more than 3 years & 330 & 180.23 & & \\
\hline Salary adequate to work & 72 & 152.1 & 8327 & \\
Salary not adequate to work & 289 & 188.2 & & \\
\hline
\end{tabular}


Table 3: Binary logistic regression on factors associated with stress

\begin{tabular}{|l|c|c|c|c|}
\hline \multicolumn{1}{|c|}{ Factor } & p-value & \multirow{2}{*}{ exponential B } & \multicolumn{2}{c|}{ 95\% confident interval } \\
\cline { 3 - 5 } & & & & upper \\
Other factors & & & & Lower \\
Age of the nursing officer & 0.092 & 0.544 & 0.269 & 1.104 \\
Marital status of the officer & 0.936 & 1.024 & 0.572 & 1.834 \\
Income of the officer & 0.753 & 0.901 & 0.472 & 1.723 \\
Number of children & 0.217 & 1.341 & 0.841 & 2.139 \\
& & & & \\
Work related factors & & & & \\
Number of night shifts per month & 0.044 & 1.839 & 1.017 & 3.326 \\
Number of double shifts in a row per month & 0.000 & 2.873 & 1.659 & 4.978 \\
Adequacy of minor staff in particular ward & 0.015 & 2.238 & 1.169 & 4.286 \\
Adequacy of nursing staff in particular ward & 0.011 & 1.963 & 1.168 & 3.299 \\
Number of shifts per month & 0.143 & 0.696 & 0.429 & 1.13 \\
Able to adjust to shift work & 0.487 & 0.822 & 0.473 & 1.429 \\
Support from the supervisor & 0.824 & 0.902 & 0.364 & 2.237 \\
Good supervision by supervisor & 0.455 & 1.261 & 0.686 & 2.319 \\
Work experience & 0.911 & 1.053 & 0.424 & 2.618 \\
Salary of adequacy to the work & 0.753 & 0.901 & 0.472 & 1.723 \\
\hline
\end{tabular}

\section{DISCUSSION}

The nursing officers working more than sixnight shifts per month had high-stress scores (median=1.62, IQR=1.41-1.79) compared to officers who were working up to six or fewer night shifts per month (median=1.41, IQR=1.33-1.70) which was statistically significant $(\mathrm{p}<0.001)$. This result was consistent with studies by Hamaideh et al., 2008, Salilih and Abajobir, 2014, and Kawano, 2008.

Nurses who work more than 40 shifts per month had a high-stress score compared to nurses who worked 40 or fewer shifts per month (median=1.53, IQR=1.351.73). This relationship was statistically significant $(p<0.001)$. Nurses who work more than ten double shifts per month had high-stress scores (median=1.70, $\mathrm{IQR}=1.56-1.82$ ), compared to nurses working less than ten double shifts per month (median=1.53, IQR=1.351.76)). This association was statistically significant $(\mathrm{p}<0.001)$. Similar results were found in a study done by Gunasekara, 2013 among psychiatric inward nursing officers in the Colombo district,

Nurses working with inadequate nursing staff had a high-stress score (median=1.68, IQR=1.47-1.79) compared to nurses who were working with adequate nursing staff $\quad$ (median=1.41, IQR=1.32-1.74). This relationship was statistically significant $(\mathrm{p}<0.05)$. A similar picture was present in nurses who were working with inadequate minor staff having high-stress scores (median 1.65, IQR=1.44-1.79) compared to those who work with adequate minor staff (median=1.37, IQR=1.301.67). This relationship was statistically significant $(\mathrm{p}<0.05)$. Glazer and Gyurak, 2008, Umro, 2013 and Tzeng and Ketefian, 2002 also found that a shortage of staff had a significant association with work-related stress.

\section{CONCLUSION}

Work-related stress was positively and significantly $(\mathrm{P}<0.05)$ associated with in number of night shifts, number of double shifts per day in a row, inadequacy of the nursing and minor staff in the ward.

\section{REFERENSES}

Abeykoon P., 2003. The implications of technology change for health care delivery in Sri Lanka. Colombo, Sri Lanka: World Health Organization. Http://Citeseerx. Ist. Psu. Edu/Viewdoc/Download.

De Silva B.S.S. and Rolls C., 2010. Health care system 
and nursing in Sri Lanka: An ethnography study. Nursing \& Health Sciences, 12(1): 33-38.

Gunasekara J., 2013. Prevalence and assosiated factors of work-related stress among clinical staff working in psychiatric inward facilities, in the district of Colombo.

Glazer S. and Gyurak A., 2008. Sources of occupational stress among nurses in five countries. International Journal of Intercultural Relations, 32(1): 49-66. https://doi.org/10.1016/j.ijintrel. 2007.10.003.

Hamaideh S.H., Mrayyan M.T., Mudallal R., Faouri I.G. and Khasawneh N.A., 2008. Jordanian nurses' job stressors and social support. International Nursing Review, 55(1): 40-47.

Jayasekara R.S., 2009. Issues, challenges and vision for the future of the nursing profession in Sri Lanka: a review. International Nursing Review, 56(1): 21-27.
Kawano Y., 2008. Association of job-related stress factors with psychological and somatic symptoms among Japanese hospital nurses: effect of departmental environment in acute care hospitals. Journal of Occupational Health, 50(1): 79-85.

Lwanga S.K., Lemeshow S. and Organization W.H., 1991. Sample size determination in health studies: a practical manual.

Salilih S.Z. and Abajobir A.A., 2014. Work-related stress and associated factors among nurses working in public hospitals of Addis Ababa, Ethiopia: a cross-sectional study. Workplace Health \& Safety, 62(8): 326-332.

Tzeng H.-M. and Ketefian S., 2002. The relationship between nurses' job satisfaction and inpatient satisfaction: an exploratory study in a Taiwan.

Umro A.I.S., 2013. Stress and Coping Mechanism among Nurses in Palestinian Hospitals, A pilot study. 